\title{
Phenomenological needs assessment of parents of children with cochlear implants
}

Firoozeh Mostafavi ${ }^{1}$, Seyed Mohammad Mahdi Hazavehei ${ }^{2}$, Mohammad Majid Oryadi-Zanjani ${ }^{3}$, Gholamreza Sharifi $\operatorname{Rad}^{4}$, Abbas Rezaianzadeh ${ }^{5}$, Leila Ravanyar ${ }^{6}$

${ }^{1}$ Ph.D. of Community Health, Associate Professor, Department of Health Education and Health Promotion, Faculty of Health, Isfahan University of Medical Sciences, Isfahan, Iran

${ }^{2}$ Ph.D. of Health Education and Health Promotion, Professor, Department of Public Health, Faculty of Health, Hamedan University of Medical Sciences, Hamedan, Iran

${ }^{3}$ Ph.D. of Speech Therapy, Assistant Professor, Department of Speech Therapy, School of Rehabilitation Sciences, Shiraz University of Medical Sciences, Shiraz, Iran

${ }^{4}$ Ph.D. of Health Education, Professor, Department of Health Education and Health Promotion, Faculty of Health, Islamic Azad University, Qom Brunch, Qom, Iran

${ }^{5}$ Ph.D. of Epidemiology, Associate Professor, Department of Epidemiology, School of Health, Shiraz University of Medical Sciences, Shiraz, Iran

${ }^{6} \mathrm{Ph} . \mathrm{D}$. Candidate of Health Education and Health Promotion, Department of Health Education and Health Promotion, Faculty of Health, Isfahan University of Medical Sciences, Isfahan, Iran

Type of article: Original

\begin{abstract}
Background: The use of cochlear implants has been a remarkable success in reducing disabilities in those with impaired hearing, which have made a significant change in the patients' quality of life. Only by relying on cochlear implants, disabilities cannot be eliminated in the hearing impaired, and, alongside this intervention, rehabilitation practices such as through family and community support are necessary.

Aim: To explain the needs of parents of children with cochlear implants to increase the quality of rehabilitation services and family-based interventions.

Methods: A descriptive phenomenology study was performed with the participation of 16 people, including eight mothers, three fathers, and five experts involved with the rehabilitation of children aged 2-7 years with cochlear implants. The research setting was centers with speech therapy service providers for hearing-impaired children in the city of Shiraz (Iran) in 2015. Information was gathered through in-depth interviews with participants and analyzed by using Colaizzi's nine-step analysis method and MAXQDA (Ver10) applications.

Results: The mean age of participants was 34 years, and the average age of diagnosis of hearing problems in children was 12 months. The obtained data from the analysis of interviews about the needs of parents of children with cochlear implants were categorized into 19 sub-contents and five contents, as follows: the need for access to health care services; psychological needs; mood-related needs of a child; educational needs and financial requirements.

Conclusion: Parents of children with cochlear implants have numerous needs, and they encounter problems based on their situation and experiences. The results indicate the necessity of close cooperation among different professionals such as an audiologist, pediatrician, psychologist, and speech therapist for the program's success.
\end{abstract}

Keywords: Needs, Parents, Cochlear Implants, Speech Therapy

\section{Corresponding author:}

Leila Ravanyar, Department of Health Education and Health Promotion, Faculty of Health, Isfahan University of Medical Sciences, Isfahan Province, Hezar Jarib Avenue, Isfahan, Iran.

Tel: +98.3136688628, Fax:+98.3136682509, Email: ravanyar2007@yahoo.com

Received: November 20, 2016, Accepted: April 26, 2017, Published: September 2017

iThenticate screening: April 24, 2017, English editing: July 03, 2017, Quality control: August 12, 2017

(C) 2017 The Authors. This is an open access article under the terms of the Creative Commons Attribution-NonCommercialNoDerivs License, which permits use and distribution in any medium, provided the original work is properly cited, the use is non-commercial and no modifications or adaptations are made. 


\section{Introduction}

Hearing problems are one of the main causes of disability. According to global statistics, more than 360 million people (328 million adults and 32 million children) have hearing impairments. Hearing impairment refers to the hearing ability of less than $40 \mathrm{~dB}$ in adults and less than $30 \mathrm{~dB}$ in children. A significant percentage of people with hearing disabilities live in low- and middle-income countries (1). The use of cochlear implants has achieved remarkable success in reducing disabilities in those with sensorineural impaired hearing, which can make a significant change in the quality of their lives. In recent years, the application of cochlear implants has been on the rise (2). Today, with advances that have taken place in the field of cochlear implants, the speech perception of the hearing-impaired has considerably improved (3). Although cochlear implants improve hearing, they do not completely eliminate disabilities in children; in other words, they cannot completely restore hearing function. Children with hearing loss and their families after cochlear implant surgery still encounter problems related to communication and education as well as the use of the sensory device itself (4). Several factors are involved in a child's ability to adapt to the new situation after cochlear implant surgery and success in training programs, especially acquiring the ability to speak and communicate. Research in the field of cochlear implantation is mainly focused on speech perception and sound production. However, some studies explore educational problems and how to engage children in learning environments (5). The success of treatment and the possibility of acquiring speech and communication skills in children who underwent cochlear implantation are affected by many factors, among which family support and follow-up treatment and speech rehabilitation by parents are important. Considering the important role of family in the rehabilitation, attention to their needs in relation to their child's problems can play an important and decisive role in the success of community-based rehabilitation programs and family-oriented interventions (6-8). Difficulties in communicating with the child will lead to delay in the child's development (9). Because a family may be effective in setting goals and determining specific needs and timely interventions, family is considered as a valuable element in providing services to children. Timely family-centered interventions in rehabilitation include understanding the family structure and system, dealing with their concerns, determining the strengths, knowledge of the personal characteristics, exchanging information, promoting the integration of children and families in the society, coordinating multidisciplinary team, etc. $(10,11)$. In assessing the perception of family structure, it is essential that the therapist takes the needs and concerns of these parents into consideration while serving them. Family needs strongly affect the family's performance and the children's interaction, which needs to be considered in the initial evaluation $(5,10,12)$. Despite the importance and role of families and parents in rehabilitation, thus far most studies were conducted and designed by a positivist approach and the theory of preset assumptions. However, a study of holistic and qualitative approaches based on the experiences of parents has never been conducted in Iran, while the research process is based on original research questions, thus considering the main question of "What are the perceived needs of parents of children with cochlear implants based on experiences?" Phenomenological method is the most useful approach for the study of the nature of a mental phenomenon in its natural environment. Accordingly, this study aimed to understand the needs of parents of children with cochlear implants in order to increase the quality of rehabilitation services and family-centered interventions performed by phenomenology.

\section{Material and Methods}

\subsection{Setting and design}

This study was conducted using a phenomenology approach. Phenomenology is a doctrine founded by Edmund Husserl, which seeks differentiation of mediated from unmediated awareness to study human consciousness from the mental phenomena that appear unmediated in the human mind and may not have even objectivity $(13,14)$. Phenomenological studies answer the question of what is an experienced phenomenon? Given the need to understand the needs of parents of children with cochlear implants experience as a human experience, descriptive phenomenology method was used in this study.

\subsection{Selection and description of participants}

In this study, the research setting was centers with speech therapy service providers for hearing-impaired children in the city of Shiraz (Iran) in 2015. Sampling methods in this study were based on purposeful and theoretical sampling methods. In the implementation process, other sources were used to study the phenomenon in order to explain it better. The sample size was determined based on reaching data saturation. In the following interview of 16 participants, in practice, data reached saturation, so that by the end of the interview, participants expressed ideas similar to the previous obtained data; thus, it did not appear to be a new concept. The participants included three fathers, eight mothers, and three experts involved in the rehabilitation of children with cochlear implants. Inclusion criteria was the ability of speaking in Farsi, full hearing ability of the children's parents, having a 2-7-year-old child 
with cochlear implants, and having a child with sensorineural-impaired hearing in the family. Additional inclusion criteria were no other disabilities other than hearing and speech disorders in children and voluntarily participation in the study. Eligible participants called for a meeting in person, and then the goals of the study were explained; meanwhile, the written consent forms were obtained. Tables 1 and 2 show the demographic characteristics of the participants in this study.

Table 1. Profile of parents participating in the study

\begin{tabular}{|l|l|l|l|l|l|l|l|}
\hline $\begin{array}{l}\text { Age of cochlear } \\
\text { implant surgery } \\
\text { (year) }\end{array}$ & $\begin{array}{l}\text { Diagnosis of hearing } \\
\text { impaired in children } \\
\text { (month) }\end{array}$ & $\begin{array}{l}\text { Gender } \\
\text { of } \\
\text { child }\end{array}$ & $\begin{array}{l}\text { Child } \\
\text { age }\end{array}$ & Occupation & Education & $\begin{array}{l}\text { Age } \\
\text { (year) }\end{array}$ & $\begin{array}{l}\text { Participant } \\
\text { number }\end{array}$ \\
\hline 2 & 8 & Boy & 6 & House wife & Diploma & 35 & Mother 1 \\
\hline 3 & 18 & Boy & 5 & House wife & Diploma & 37 & Mother 2 \\
\hline 2 & At birth & Boy & 2 & House wife & Diploma & 33 & Mother 3 \\
\hline 1 & At birth & Boy & 2 & House wife & Diploma & 25 & Mother 4 \\
\hline 2 & 7 & Girl & 4 & House wife & Diploma & 32 & Mother 5 \\
\hline 3 & 24 & Girl & 3 & House wife & Primary & 23 & Mother 6 \\
\hline 3 & 3 & Boy & 7 & House wife & $\begin{array}{l}\text { Secondary } \\
\text { guidance }\end{array}$ & 33 & Mother 7 \\
\hline 2 & 18 & Boy & 6 & Teacher & Bachelor & 42 & Mother 8 \\
\hline 3 & 5 & Boy & 7 & $\begin{array}{l}\text { Emergency } \\
\text { medical services }\end{array}$ & Diploma & 31 & Father 1 \\
\hline 4 & 18 & Girl & 6 & Farmer & Primary & 33 & Father 2 \\
\hline 3 & 32 & Girl & 5 & Teacher & Bachelor & 49 & Father 3 \\
\hline
\end{tabular}

Table 2. Profile of experts participating in the study

\begin{tabular}{|l|l|l|l|l|}
\hline Work experience & Age (year) & Specialty & Education & Participant number \\
\hline 6 & 31 & Speech therapist & Bachelor & Specialist 1 \\
\hline 2 & 28 & Speech therapist & Bachelor & Specialist 2 \\
\hline 7 & 29 & Speech therapist & Bachelor & Specialist 3 \\
\hline 19 & 42 & Speech therapist & Master & Specialist 4 \\
\hline 8 & 45 & Psychologist & Bachelor & Specialist 5 \\
\hline
\end{tabular}

\subsection{Data collection, analysis, and assurance of rigor}

The method of collecting data in this study was through semistructured interviews. In the first and second interviews, questions were generally asked, such as: "What is the experience of the needs of parents of children with cochlear implants?" Then more specific questions were asked: When you think about the needs of parents of children with cochlear implants what comes to your mind? Additional questions were asked only when it was necessary to clarify. When participants described their experiences for more clarification, the interview was considered ended. Interviews lasted between 22 to 70 minutes. Interviews were done in one of the rooms of rehabilitation centers in the right time and place where participants felt comfortable, according to environmental factors, time, and circumstances of the participants and their wish to be asked individually in one shift. The interviews were recorded with the consent of the interviewees; then, at the first opportunity, they were written word by word; soon after, the handwritings were transferred to the software to be analyzed. According to the fact that, in qualitative research, the researcher needs to be immersed in information. Therefore, interviews were reviewed on several occasions and were checked again. In the present study, in order to exclude any understanding, judgment, and knowledge for the right achievement, the bracket (parentheses) method was used, which means that the mental background of the person was written, and they were not addressed as far as possible in the interview process. After analyzing the interviews and extracting the concepts, subsequent interviews were semistructured, originating from more inferential leading questions from previous interviews regarding the parents' needs, and the factors influencing the study were carried out. The data analysis method was based on Colaizzi, which included a description of the phenomena, collecting descriptions of examples of the phenomenon, the study of all descriptions and examples, referring to the handwritten notes and extracts from important sentences, pulling out the meaning of each important sentence, organizing meanings formulated in a clusters theme and providing comprehensive descriptions, referring to characterized samples for validation, and to add new data to comprehensive descriptions during authentication. Versions of each interview were read; then, they were required to extract important sentences and the meaning of 
each sentence of the language written by the researcher. An example of two extracted themes is presented in Table 3. The themes were organized based on their meaning in clusters to obtain a description of these requirements. In order to facilitate the analysis, MAXQDA version 10 was used. During the study, some methods were used to ensure accuracy and reliability; in regards to this, four proposed criteria by Astrabrt and Carpenter were used. One of the best ways to build credibility is through long-term involvement in the research, in which the researcher is given a year to become involved with the subject and the people related to it. Review was done by the participants to verify the extracted data and codes that were used or modified. Thus, after coding each interview, the participants returned to the accuracy of their interpretations of the code to ensure that codes that did not represent their views were corrected. To determine the appropriateness of the findings, results were shared with the number of parents who did not participate in research findings to confirm that they fit. In this study, in order to create stability and reliability of data at a time and the same conditions, there is an outside observer who has no connection with the research project. His perception was assessed with the project. In addition, codes and themes extracted at each stage of the collaboration have been explained with researchers and people familiar with qualitative analysis to verify the process (confirmability). In order to make transferability and fittingness of solutions appropriate samples, collection and analyzing data concurrently, methodological coherence and theoretical thinking were used.

Table 3. Examples of important statements of the participants in the study and their meanings

\begin{tabular}{|l|l|l|}
\hline Theme: & Important statements & Meaning \\
\hline Child interactions & $\begin{array}{l}\text { My daughter had difficulty in } \\
\text { communicating with other kids; she claims } \\
\text { everything for herself }\end{array}$ & $\begin{array}{l}\text { She finds her child has difficulty in } \\
\text { communication with others }\end{array}$ \\
\hline $\begin{array}{l}\text { Working skills with } \\
\text { child }\end{array}$ & $\begin{array}{l}\text { I would like to know how I could work with } \\
\text { my child at home; she does not cooperate } \\
\text { with me }\end{array}$ & $\begin{array}{l}\text { He feels more need to know the skill of } \\
\text { working with child at home. } \\
\text { Due to lack of skills, cannot gain the } \\
\text { cooperation of the child at home. }\end{array}$ \\
\hline $\begin{array}{l}\text { Participation in } \\
\text { educational } \\
\text { meetings }\end{array}$ & $\begin{array}{l}\text { We do not have a detailed plan of the holding } \\
\text { classes for parents }\end{array}$ & $\begin{array}{l}\text { Parents are required to attend educational } \\
\text { classes }\end{array}$ \\
\hline $\begin{array}{l}\text { Knowing how to deal } \\
\text { with the child }\end{array}$ & $\begin{array}{l}\text { I would like to know more about attention } \\
\text { and concentration of my child, how to catch } \\
\text { his/her attention later than I would like to } \\
\text { know his/her fear much more }\end{array}$ & $\begin{array}{l}\text { He feels more need to know regarding } \\
\text { his/her child's condition }\end{array}$ \\
\hline
\end{tabular}

\subsection{Ethical considerations}

This paper results from a PhD thesis in health education and health promotion, which was approved by the ethics committee of Isfahan University of Medical Sciences. After administrative procedures and introducing the researcher to the research environment, at the time of interview, the aim of the study and the procedure were fully explained to the participants; after they agreed to participate in the study, verbal and written informed consent were obtained. The consent form included information such as optional participation in the study, the right to withdraw from the study at any stage of the investigation, the confidentiality of the information, and that their denial from contributing to the study had no effect on the treatment procedure of a participant's child. In the written manuscripts, numbers were used instead of participant names.

\section{Results}

\subsection{Sociodemography}

The average age of participants was 34 years, and the age of children with cochlear implants was $2-7$ years. The average age of diagnosis of hearing problems was 12 months, and the mean age of cochlear implants surgery was 2.5 years. Data obtained from the analysis of interviews regarding the needs of parents of children with cochlear implants were categorized in 19 themes and five clusters, which are shown in Table 4. Five main clusters include need for access to health care, psychological needs, needs related to emotional moods of children, educational needs, and financial needs. 
Table 4. Clusters and themes of study

\begin{tabular}{|c|c|}
\hline Clusters & Themes \\
\hline \multirow{3}{*}{ The needs for access to health care } & Access to treatment facilities in the area \\
\hline & No sensory devices \\
\hline & The need for screening facilities in the area \\
\hline \multirow[t]{5}{*}{ Psychological needs } & Raising confidence \\
\hline & Positive outlook on life and the future \\
\hline & Controlling anger and stress \\
\hline & Mood disorders \\
\hline & Resiliency \\
\hline \multirow[t]{3}{*}{ Mood- related issues in children } & Social interaction of child \\
\hline & Behavioral disorders in child \\
\hline & Child sleep \\
\hline \multirow[t]{4}{*}{ Training needs } & Skills in educating children at home \\
\hline & Information about congenital diseases \\
\hline & Participation in education classes \\
\hline & Training for preparation before cochlear implant surgery \\
\hline \multirow[t]{3}{*}{ Financial needs } & Financial need for treatment practices \\
\hline & Financial needs for rehabilitation activities \\
\hline & Lack of support from protective organizations \\
\hline
\end{tabular}

\subsection{Need for access to health care}

The need for access to health care is divided into three themes, including access to treatment facilities in the area, the need for screening facilities in the area, and lack of receiver device. One of the most important steps necessary to accelerate the healing process is early diagnosis, which, by speeding up rehabilitation programs, can have a significant impact on reducing the relevant complications and disabilities. According to Table 1 and the column related to the age of diagnosis of impaired hearing, we can conclude that this issue is one of parents' main concerns. One of the participants in this case expressed his feelings as follows: "Unfortunately, when my son was born, the screening test was not available in our city." Access to medical facilities in the area also was one of the themes in this category. This need, as expressed by most participants, in fact, refers to a kind of inequality in access to health care. It is also one of the major problems of rehabilitation and timely and appropriate treatment for families. In this regard, one of the participants said: "We used to come to Shiraz twice a week for our child treatment until we became really tired, so we decided to move to Shiraz, as it was easier for me to commute to work alone than coming to Shiraz with my wife and our child regularly." Another theme, as mentioned by most participants, was the lack of sensory device that itself reflects a lack of access to medical facilities and equipment.

\subsection{Psychological needs}

Psychological needs were divided into five themes, including raising self-esteem, positive outlook on life and the future, anger and stress, mood disorders, and resiliency. Parental participation is one of the most important factors influencing the increase in parental involvement in treatment and rehabilitation as well as the success of rehabilitation. The attention to psychological needs can play a significant role in a child's rehabilitation process. One need that participants referred to is the need to increase self-confidence, as one of the participants stated: "I have no confidence at all; if I had confidence in myself, I could help myself and also my daughter." Another participant also mentioned that, "We should accept ourselves; we should bolster our self-confidence." Another theme is the positive outlook on life and the future. In this regard, one of the participants stated: "I am afraid of his future, whether his speech will be clear or not, or as he grows older what the future might hold for him. Or, for example, if somebody could take care of him if I would not available ... I am not sure if these classes will continue or not." Another participant said: "I'm always worried, what's their future, both in terms of employment, and also for marriage and, from now on I think about him, for example, with whom, with someone like himself. In this regard, I am always concerned." Controlling anger and stress was another theme. In this regard, one participant stated that: "Maybe my son's problem affected my mentality because I was not like this; I used to cope with a problem always with smile, but now I cannot laugh, and whenever a small thing happens, I get angry." Another participant said, "I wish to get angry less. When I get angry, I might punish her." One of the other themes was mood disorders comprising the three sub-categories of irritability, sadness, and getting impatient. In this case, one of the participants said, "I became very impatient and nervous and so that sometimes my husband says that you were not like this. I get angry on small 
things, and I become upset very fast, so I really need to control this problem because it affected my family relationships and also work with my child. Another participant stated that, "I was very happy, and wherever I used to laugh a lot, I was an example for my laughs and happiness. Now I cannot laugh anymore like before; it has reached to 30 percent compared with the past. I am less happy; nothing makes me happy from the bottom of my heart anymore. I really want to be the person I was before and this bothers me. Even this issue is bothering my family and affected everything." Resiliency is the next theme; in this case, one participant said: I am tired of coming here every day. I tell myself that my daughter might become tired too because I work with her at home and sometimes she does not collaborate. I bring her here five sessions per week. Commuting here is tiring, and I cannot manage the housework. I used to spend most of my time at home to organize everything, but now I have to prepare the lunch the night before, and I have to return home at noon to do housework. I cannot do all together, and this is exhausting. This makes me depressed, and I feel I cannot stand it anymore. I used to be at home more often, and sometimes I wish the situation was like before."

\subsection{Needs related to emotional moods of children}

The emotional needs of the child were divided into three themes, including social interactions, behavioral disorders, and sleep. Children's social interaction is another theme expressed by participants as one of their main problems with their child. In this case, one of the participants said, "My daughter has difficulty in communicating with other kids; she somewhat owns everything; for example, she has two cousins, and she takes her toys and does not allow them to play with them. I think she doesn't fully understand when I am talking to her, and when she gets older and to grasp my words she will not do this. Sometimes I do not know what to do when she gets in trouble with her peers. Sometimes I think she likes to play alone." Another theme was behavioral disorders in children. In this regard, one participant said: "If they sit, we can work with them." Sometimes they are very stubborn. Children with hearing problems are spiteful and have lots of excuses, and their demands are very high. It means that, whatever they want, we have to prepare for them and are too stubborn to work and cooperate in training, and it is hard to handle them." Another theme is child sleep disorder. In this regard, one of the participants said, "My daughter has behavioral problems; for instance, wherever we go she does not lift her head, and I must hug her and take her. She resists coming in, and she wants me to hug her. She has sleep problems, too, and she is awake until midnight."

\subsection{Educational needs}

Educational needs are divided into five themes: skills in educating children at home, information about congenital diseases, attending educational classes, preparatory training before cochlear implant surgery, and training related to child behavior. One of the themes, as emphasized by participants, was the lack of appropriate skills in educating children at home. One participant said, "I have not received any training on how to work with children. I like to know how to work with my child at home; she does not cooperate with me at home at all." Another theme is having information about congenital diseases. In this respect, one of the participants said, "As we did not have the same case in family and relatives, we had no information about congenital diseases and nobody had told us anything about it." Another theme, as mentioned by participants, was the need to attend educational classes. In this case, one of the participants said: "I think our kids should go more classes, more classes are needed, the number of sessions is limited, and if my kid was able to attend the class one hour more per week (three sessions, private classes per week), perhaps she would be much better." One of the participating experts in this regard said, "We do not have a detailed plan of holding training classes for parents, but we do feel such need; we can see we need to work with just parents at least four to five sessions at first." One of the themes mentioned by participants is the preparatory training before cochlear implant surgery. In this case, one participant said, "There is no preparation before surgery; if it to be done, it will be in a very imperfect process. There is just a commission for the child, and then we are said that your turn is in six months to one year. Then, within this period, two to three training sessions are held, which is insufficient, and this imperfect process cannot change the parents' mindset regarding the outcome. Parents normally encounter an incorrect mindset after surgery, which makes it harder for them to work with their children." Another theme is training associated with children's behavioral problems, which, in this regard, one of the participants said, "I am not aware of my child's temper. I do not know him enough to be able to work with him properly. I need to get necessary training and education to be able to work with my child." One of the participants said: "I really like to know more about his attention and focus and how I can draw his attention. Also, I like to know more about his fears, but I have not received any training in this regard."

\subsection{Financial needs}

Financial needs are divided into three themes, including financial requirements for therapeutic interventions, financial needs for the rehabilitation, and lack of support by protective organizations. Financial requirements for 
therapeutic interventions and, in particular, for costs associated with cochlear implant surgery are among the needs mentioned by the participants. In this case, one of the participants said: "We needed 60 million Rials for my daughter's operation, and we did not have that much money, so my mother in law gave us 1 million Rials and my brother 7 million Rials. We also had a car, which we sold to do the surgery." Another participant said: "We sold our house for surgery costs and we borrowed money. We have still seven to eight loan installments, and we are under financial pressure." Another theme of financial needs is rehabilitation; in this case, one participant said, "Besides here, if I were able to take my child to private speech, maybe she would be better now or if I would take she to normal school, and she could be with normal child. Unfortunately, we have financial problems, and I am not able to do so many things for my child." Another participant also said, "I really wanted to be financially capable of sending my child to private classes; for example, instead of being here half an hour or 45 minutes, she could be in the private class one, two, or three hours, and so she could be ahead in both speaking as well as her future education and training." Another theme is the lack of support by protective organizations; in this regard, one of the participants said, "Considering my financial situation, I expected at least an organization to support me in some ways; unfortunately, they did not help me. I need to say that it was really hard for us because we did not have any source of income, and my father just had a heart surgery; they were in tough situation both mentally and financially, and none of the organizations addressed my request appropriately."

\section{Discussion}

This study offers unique research, which directly reflects the needs expressed by parents of children with cochlear implants. According to our literature review, there has been no similar study in Iran and only few studies conducted at the international level. The results of this study indicate that parents of children with cochlear implants face several problems, and, considering their situations, they encounter these problems based on their experiences. One of the needs expressed by participants was access to services; this need reflects the fact that the required services for responding to these needs has not yet been properly developed. The families with disabled children should search for service providers, and most of them have to change their place of living. This is indicative of the fact that the lack of access to special services imposes a disproportionate burden on the families. Similar to our finding, in a study conducted in Turkey, this need also was expressed by parents (12). One of the most important steps for the management and success of the therapeutic interventions and rehabilitation in patients with hearing and speech disorders is timely detection and action, which requires access to high-quality screening and diagnosis services in the area. The delay in detection of the problems in this study verifies the need for access to appropriate services. However, access to the services affected by the location and socioeconomic status of the families (12) indicates that, according to the principle of equality in health services, this problem is a manifestation of inequality in access to services.

Psychological needs also are among the factors that involve parents. Several studies have investigated mental health problems as an effective factor on the rehabilitation process. Thus, numerous studies have shown that the parents of children with cochlear implants even have higher stress level than do parents of children who use hearing aids (1517). Some studies have shown that parental stress increases with increasing duration of rehabilitation (16, 18-20). Several reasons have been suggested to be associated with this increase, including encounters with specific requirements for children's education, school, increased social interactions, and high level of expectations, although study results are controversial (8). But what is important is that the high psychological pressures on parents and not paying attention to them can have a negative effect on the results and the success of rehabilitation. Several studies have been conducted in regards to the impact of having children with disabilities on the mental health of a family; the results indicate the presence of mental disorders and problems in these families $(2,21,22)$. The participants expressed that they also are involved with mood and behavioral issues of the children, which highlights that more attention should be paid to the behavioral and educational issues of children. Some studies showed that children with disabilities alongside the disability itself also suffer from other behavioral disorders such as hyperactivity and low concentration, which makes it difficult for parents to work with these children (12). These parents at each new stage of their child's life (school, teens, graduation, marriage, etc.) once again experience problems associated with their child, while parents of children with poor hearing seldom encounter such problems (23). Participants also expressed concern about educational needs. Parents of hearing-impaired children should acquire lots of information about impaired hearing. This can profoundly affect the way of raising such children. Much specialized information presented by experts are in scientific language and therefore are completely incomprehensible for parents. Many parents will realize in later years that they had other options. Some of them try very hard to get the information, while others do not have necessary determination; they get most of the information randomly. In this regard, some parents join support groups that consist of other parents with hearing-impaired children or connect with associations 
and community centers $(24,25)$. Some parents have pointed out that they are under pressure because they feel huge responsibility for the success of their children's lives. It also creates fear in parents of young children, while parents of older children feel guilty about failure to perform the proper functions and responsibilities in raising their child. Many parents feel tired of acquiring information and sometimes just want to be the mother/father, not a teacher or trainer $(24,26)$.

According to the studies conducted on parents of children with impaired hearing, parents stated that they are interested in obtaining complete information concerning their child's hearing problem. It also was stated that they often prefer written information (27). Some participants claimed to have obtained inaccurate and misleading information from the doctors and medical staff, which implies the lack of sufficient information and knowledge of service providers and health professionals about the hearing problems and rehabilitation practices. For instance, the results of a study conducted in Turkey underline the importance of continuing training for professionals in the region. The staff of rehabilitation services should train the target population, including early interventionists, pediatrician's teachers, and teachers of the hearing-impaired students, speech-language pathologists, and audiologists (12). Moreover, financial need has been regarded as one of the factors that affect lifestyle, the quality of care, and participation of parents in rehabilitation programs. Several studies have addressed this need in families with hearing-impaired children $(28,29)$. Some studies cited that some parents involved with care of children with disabilities have to quit their jobs, which creates financial problems for the families $(30,31)$. In this study, travel and commuting costs to the centers for receiving rehabilitation services are regarded as one of the financial problems by participants. This also was reported in a study conducted on families with children with cochlear implants in Turkey (12). One of the items cited by participants is lack of support by advocacy and the insurer organizations. The problem arises from the lack of knowledge and familiarity of parents with protective systems that this itself is due to lack of notification and information systems $(12,32)$.

\section{Limitations and implications for research}

According to the results of this study, parents of children with cochlear implants have numerous needs and require psychosocial support. This framework was introduced for the needs of this population based on the conditions prevailing in this group. One of the limitations of this study is the dependency of the results to time and location, which makes the generalization difficult. Another important factor is change in requirements by age, especially when children grow older and encounter the education system. The target population in this study was children under six years of age; it is recommended that educational needs and issues related to education systems that parents are involved with to be investigated in future studies. By improving community-based rehabilitation and familycentered interventions and taking into account actual needs of the recipients of services to enhance the required interventions and their effectiveness.

\section{Conclusions}

The results indicate that family needs and dynamics, counseling programs according to the specific needs of this demographic group, and close cooperation between different professionals such as audiology, pediatric, and psychiatric specialists, speech therapist, etc., for the success and responsiveness of rehabilitation program are necessary. Finally, it should be noted that all the mentioned items in this study are effective in the success of interventions.

\section{Acknowledgments:}

This article comes as part of a $\mathrm{PhD}$ thesis in health education and health promotion approved by Isfahan University of Medical Sciences (Ref. No. 393789). The authors would like to thank all parents who participated in the research and the personnel of rehabilitation centers. The authors also appreciate the cooperation of Dr. Khorasani-Zavareh for the efforts on assessing the extracted codes.

\section{Conflict of Interest:}

There is no conflict of interest to be declared.

\section{Authors' contributions:}

All authors contributed to this project and article equally. All authors read and approved the final manuscript. 


\section{References:}

1) World Health Organization. Deafness and hearing loss. 2015. Available from: http://www.who.int/mediacentre/factsheets/fs300/en/.

2) Zaidman Zait A, Most T. Cochlear implants in children with hearing loss: Maternal expectations and impact on the family. Volta Rev. 2005; 105(2): 129-50.

3) Dillon MT, Adunka OF, Anderson ML, Adunka MC, King ER, Buchman CA, et al. Influence of age at revision cochlear implantation on speech perception outcomes. JAMA Otolaryngol Head Neck Surg. 2015; 141(3): 219-24. doi: 10.1001/jamaoto.2014.3418. PMID: 25611857.

4) Meinzen-Derr J, Wiley S, Grether S, Choo DI. Children with cochlear implants and developmental disabilities: a language skills study with developmentally matched hearing peers. Res Dev Disabil. 2011; 32(2): 757-67. doi: 10.1016/j.ridd.2010.11.004. PMID: 21129916.

5) Wheeler A, Archbold SM, Hardie T, Watson LM. Children with cochlear implants: The communication journey. Cochlear Implants Int. 2009; 10(1): 41-62. doi: 10.1179/cim.2009.10.1.41. PMID: 19025886.

6) Bat-Chava Y, Martin D. Sibling relationships for deaf children: The impact of child and family characteristics. Rehabil Psychol. 2002; 47(1): 73-91. doi: 10.1037/0090-5550.47.1.73.

7) Bat - Chava Y, Martin D, Kosciw JG. Longitudinal improvements in communication and socialization of deaf children with cochlear implants and hearing aids: Evidence from parental reports. J Child Psychol Psychiatry. 2005; 46(12): 1287-96. doi: 10.1111/j.1469-7610.2005.01426.x. PMID: 16313429.

8) Zaidman-Zait A. Everyday problems and stress faced by parents of children with cochlear implants. Rehabil Psychol. 2008; 53(2): 139. doi.10.1037/0090-5550.53.2.139.

9) Melnyk BM, Alpert - Gillis L, Feinstein NF, Fairbanks E, Schultz - Czarniak J, Hust D, et al. Improving cognitive development of low - birth - weight premature infants with the COPE program: A pilot study of the benefit of early NICU intervention with mothers. Res Nurs Health. 2001; 24(5): 373-89. PMID: 11746067.

10) Cleveland LM. Parenting in the neonatal intensive care unit. J Obstet Gynecol Neonatal Nurs. 2008; 37(6): 666-91. doi: 10.1111/j.1552-6909.2008.00288.x. PMID: 19012717.

11) McKellin WH. Hearing impaired families: The social ecology of hearing loss. Soc Sci Med. 1995; 40(11): 1469-80. doi: 10.1016/0277-9536(94)00358-Z. PMID: 7667652.

12) Yucel E, Derim D, Celik D. The needs of hearing impaired children's parents who attend to auditory verbal therapy-counseling program. Int J Pediatr Otorhinolaryngol. 2008; 72(7): 1097-111. doi: 10.1016/j.ijporl.2008.03.020. PMID: 18468697.

13) Chan GK, Brykczynski KA, Malone RE. Interpretive phenomenology in health care research: Sigma Theta Tau; 2010.

14) Finlay L. Phenomenology for therapists: Researching the lived world: John Wiley \& Sons; 2011. doi: $10.1002 / 9781119975144$.

15) Burger T, Spahn C, Richter B, Eissele S, Löhle E, Bengel J. Parental distress: The initial phase of hearing aid and cochlear implant fitting. Am Ann Deaf. 2005; 150(1): 5-10. doi: 10.1353/aad.2005.0017. PMID: 15969219.

16) Quittner AL, Steck JT, Rouiller RL. Cochlear implants in children: a study of parental stress and adjustment. Am J Otol. 1991; 12: 95-104. PMID: 2069197.

17) Spahn C, Richter B, Burger T, Löhle E, Wirsching M. A comparison between parents of children with cochlear implants and parents of children with hearing aids regarding parental distress and treatment expectations. Int J Pediatr Otorhinolaryngol. 2003; 67(9): 947-55. doi: 10.1016/S0165-5876(03)00160-5. PMID: 12907049.

18) Perold JL. An investigation into the expectations of mothers of children with cochlear implants. Cochlear Implants Int. 2001; 2(1): 39-58. doi: 10.1179/cim.2001.2.1.39. PMID: 18792003.

19) Purdy S, Chard L, Moran C, Hodgson S. Outcomes of cochlear implants for New Zealand children and their families. Ann Otol Rhinol Laryngol Suppl. 1995; 166: 102-5. PMID: 7668593.

20) Richter B, Spahn C, Zschocke I, Leuchter M, Laszig R, Löhle E. [Psychological stress, knowledge and treatment expectation of parents with a child managed by cochlear implant]. HNO. 2000; 48(9): 675-83. doi: $10.1007 / \mathrm{s} 001060050638$. PMID: 11056856.

21) DesJardin JL, Eisenberg LS. Maternal contributions: Supporting language development in young children with cochlear implants. Ear Hear. 2007; 28(4): 456-69. doi: 10.1097/AUD.0b013e31806dc1ab. PMID: 17609609 . 
22) Meinzen-Derr J, Lim LH, Choo DI, Buyniski S, Wiley S. Pediatric hearing impairment caregiver experience: Impact of duration of hearing loss on parental stress. Int J Pediatr Otorhinolaryngol. 2008; 72(11): 1693-703. doi: 10.1016/j.ijporl.2008.08.005. PMID: 18819718.

23) Janjua F, Woll B, Kyle J. Effects of parental style of interaction on language development in very young severe and profound deaf children. Int J Pediatr Otorhinolaryngol. 2002; 64(3): 193-205. doi: 10.1016/S0165-5876(02)00069-1. PMID: 12090947.

24) Hintermair M. Parental resources, parental stress, and socioemotional development of deaf and hard of hearing children. J Deaf Stud Deaf Educ. 2006; 11(4): 493-513. doi: 10.1093/deafed/enl005. PMID: 16809431.

25) Anagnostou F, Graham J, Crocker S. A preliminary study looking at parental emotions following cochlear implantation. Cochlear Implants Int. 2007; 8(2): 68-86. doi: 10.1179/cim.2007.8.2.68. PMID: 17549804.

26) Plessow-Wolfson S, Epstein F. The experience of story reading: Deaf children and hearing mothers' interactions at story time. Am Ann Deaf. 2005; 150(4): 369-78. doi: 10.1353/aad.2005.0046. PMID: 16466192.

27) Young A. Parenting and deaf children: A psycho-social literature based framework. London : National Deaf Children's Society; 2003.

28) Knussen C, Sloper P. Stress in families of children with disability: A review of risk and resistance factors. J Ment Health. 1992; 1(3): 241-56. doi: 10.3109/09638239209005457.

29) Alaee N, Shahboulaghi FM, Khankeh H, Mohammad Khan Kermanshahi S. Psychosocial Challenges for Parents of Children with Cerebral Palsy: A Qualitative Study. J Child Fam Stud. 2015; 24(7): 2147-54. doi: 10.1007/s10826-014-0016-3.

30) Sen E, Yurtsever S. Difficulties experienced by families with disabled children. J Spec Pediatr Nurs. 2007; 12(4): 238-52. doi: 10.1111/j.1744-6155.2007.00119.x. PMID: 17956372.

31) Taanila A, Syrjälä L, Kokkonen J, Järvelin MR. Coping of parents with physically and/or intellectually disabled children. Child Care Health Dev. 2002; 28(1): 73-86. PMID: 11856190.

32) Shlay AB, Weinraub M, Harmon M, Tran H. Barriers to subsidies: Why low-income families do not use child care subsidies. Soc Sci Res. 2004; 33(1): 134-57. doi: 10.1016/S0049-089X(03)00042-5. 